Revista de Derecho

de la Pontificia Universidad Católica de Valparaíso

XXXII (Valparaíso, Chile, $1^{\text {er }}$ Semestre de 2009)

[pp. $183-208]$

\title{
EL SINGULAR RENACIMIENTO DE LA AUTONOMÍA DE LA VOLUNTAD Y LA "LOCATIO CONDUCTIO OPERARUM ET OPERIS” COMO CONSECUENCIA DE LA PRESENTE DEPRESIÓN ECONÓMICA
}

["The Singular Renaissance of the Autonomy Will's and the "locatio conductio operarum et operis" Like Consequence of the Present Economic Crisis"]

\section{Luis Rodríguez EnNes* \\ Universidad de Vigo}

\section{RESUMEN}

El trabajo versa sobre la insuficiencia del Derecho común para dar respuesta a la llamada "cuestión social", que se presentó como la causa principal del nacimiento de un contrato de trabajo diferenciado de la clásica "locatio conductio operarum". No obstante, hoy, con la crisis económica, los principios neoliberales (contratos discrecionales, contratos de adhesión, flexibilización del empleo, etcétera) han hecho perder su especialidad a la moderna contratación laboral y provocado su reintegración en la tradicional órbita iusprivatista de progenie romana.

Palabras Clave: Cuestión social Contrato de trabajo - Crisis económica - Locatio conductio operarum et operis.

\section{Abstract}

Arises the need to analyse, according to present economic depression, the notorious insufficiency of the common law to confront the named "social problem". That is the principal cause of the born of a labour contract different to the classical "location conductio operarum". But, today with the economic crisis, the new liberalisms principles (contract discretionary, membership contracts and the employment's flexibility) did cause your speciality to the modern labour agreement provoking your reintegration in the traditional private law, originally roman.

KeYwords: "Social Problem" - Labour contract - Economic crisis - Locatio conductio operarum et operis.

* Catedrático de Derecho Romano de Facultad de Derecho de la Universidad de Vigo. Domicilio Postal: Facultad de Derecho. Campus Universitario Las Lagunas, 32004 Ourense, España. Correo electrónico: ennes@uvigo.es 


\section{INTRODUCCIÓN}

Ya en 2002, con motivo del V Congreso Internacional y VIII Iberoamericano de Derecho Romano, que tuvo lugar en la universidad brasileña de Fortaleza, me cupo el honor de pronunciar una conferencia plenaria acerca del tema: "La crisis de la autonomía de la voluntad y la aparición del moderno contrato de trabajo" . Allí puse de manifiesto que jurídicamente el contrato de trabajo es un contrato de arrendamiento de servicios, sólo que las circunstancias sociales le han impuesto una reglamentación cuidadosa y especial que no tuvo el arrendamiento primitivo y que, en cierto modo, muda su naturaleza. Las relaciones laborales han seguido un proceso evolutivo en el que el nexo contractual que les sirve de base fue lenta y penosamente discurriendo por ese cauce sinuoso, inicialmente asentado sobre el lecho inestable de la vieja locatio conductio operarum, para devenir primero en el decimonónico arrendamiento liberal de servicios y luego, aunque con perfiles siempre borrosos, en el contrato de trabajo que, a fin de cuentas, no es sino una variable de ese arrendamiento de servicios al que la presión ejercida por quienes nuestro Código Civil aún denomina "criados y trabajadores asalariados" logró adosar el calificativo de "laboral"

En la ya citada conferencia aludía a que debido en gran parte a los ciclos económicos adversos y al resurgir del pensamiento que ha venido a llamarse "neoliberal", se ha suscitado una cierta vis repulsiva hacia el contrato de trabajo de corte clásico y un intento de reducir sus fronteras a costa del singular renacimiento de la locatio conductio operarum. La macrocrisis económica en la que estamos inmersos -comparable a la Gran Depresión de 1929- demuestra el carácter muy actual y polémico del tema elegido, puesto que en él se halla implicada nada menos que la capital cuestión del ámbito de la relación laboral. Ello nos evidencia la perennidad de los problemas centrales de las disciplinas jurídicas.

Como es sabido, el Derecho Civil de finales del siglo XIX y principios del siglo XX se mostraba incapaz de hacer frente a las necesidades de los trabajadores por cuenta ajena y dependientes. Esto justificó el nacimiento de una nueva rama del ordenamiento jurídico: el Derecho del Trabajo. Cuando se pensaba que las características distintivas del contrato de trabajo estaban suficientemente elaboradas, pulidas y bruñidas con esmero

${ }^{1}$ Cfr. Rodríguez Ennes, La crisis de la autonomía de la voluntad y la aparición del moderno contrato de trabajo, en $A$ autonomía da vontade e as condiçóes Gerais do contrato, de Roma ao direito actual. Anais do V Congreso Internacionaly VIII Iberoamericano de Derecho Romano (Fortaleza, Ceará, Brasil, 2002), pp. 629 ss.

${ }^{2}$ Por todos, Luján Alcaraz, La contratación privada de servicios y el contrato de trabajo (Madrid, 1994), p. 30, con abundante bibliografía al respecto. 
técnico de doctrinarios y jueces, emergen de modo creciente modalidades de trabajo que, aún no ajustándose a esos límites técnico-jurídicos tan cuidadosamente acuñado y perfilado, sacan a la luz la patente necesidad de una protección jurídica hoy inexistente ${ }^{3}$.

La magna protección dispensada a lo largo de más de un siglo por la legislación social a los trabajadores que podemos llamar "comunes", está sufriendo -al socaire de la debacle financiera- los embates de manifestaciones de signo inverso conducentes a una creciente privatización del contrato de trabajo en detrimento de la presunción de laboralidad. Como acertadamente señala Montoya Melgar, "el fenómeno no es nuevo: las formas jurídicas reciben el desafío de las exigencias sociales”.

Por utilizar una imagen, el Derecho del Trabajo se asemeja a una ciudadela o invernadero, donde los prestadores de trabajo quieren entrar masiva e incondicionalmente, por el alto "estándar" de protección que les confiere la legislación laboral. Fuera queda el páramo del Derecho Civil y Mercantil, el frío que da la desprotección social. En el primer caso, un despliegue fabuloso de heteronomía, de origen estatal o convencional, protege al trabajador, que ve así reconocidos y salvaguardados sus derechos. Hay un alto grado de desequilibrio con respecto a la otra parte del contrato: el empleador o empresario. En suma, el Derecho del Trabajo trata desigualmente a los desiguales para hacerlos más iguales. Y en esa tarea se pone, en uno de los platillos de la balanza, todo el acervo normativo laboral, que deja, quizá como consecuencia obligada, muy poco margen a la autonomía de la voluntad. Y en el otro polo nos encontramos a una serie de personas que materialmente hacen lo mismo, pero formalmente lo hacen de modo diferente, sobre la base de contratos que, aún perteneciendo al vasto campo de las obligaciones de facere se califican como de naturaleza jurídica distinta. Aquí existe un amplio margen para la autonomía de la voluntad, comenzando por la propia calificación del contrato o, si se quiere, por la elección del modo jurídico de la prestación. Para la más moderna doctrina laboralista ${ }^{5}$, es cierto que la presunción de laboralidad que consagra el artículo 8 del Estatuto de los Trabajadores es cada vez menos firme, siendo

${ }^{3}$ Montoya Melgar, "Presentación" a Sagardoy Bengoechea, Los trabajadores autónomos hacia un nuevo Derecho del Trabajo (Madrid, 2004), p. 9.

${ }^{4}$ Ibid.

${ }^{5}$ Véase, entre otros, González Ortega, La presunción de existencia del contrato de trabajo, en Cuestiones actuales de Derecho del Trabajo (Madrid, 1990); RodríGueZPIÑEro, La huida del Derecho del Trabajo, en Relaciones Labores. Revista Crítica de Teoría y Práctica 1 (1992); El mismo, Diritto del lavoro e mercato, en Lavoro e Diritto 1 (1995); El mismo, La voluntad de las partes en la calificación del contrato de trabajo, en Relaciones Labores. Revista Crítica de Teoría y Práctica 2 (1996). 
por el contrario cada vez más relevante la voluntad de las partes a la hora de escoger el contrato civil, mercantil o laboral que canalice la prestación comprometida. El tema tiene una gran trascendencia, puesto que hoy en día se practica una especie de maniqueísmo totalitario. El rígido carácter bipolar del Derecho del Trabajo determina que una relación sea laboral o no, produciéndose la aplicación en bloque del Derecho laboral o una exclusión, también en bloque, de este mismo ordenamiento ${ }^{6}$. Tal rigidez es una de las causas en la determinación del ámbito de lo laboral. En las disputas judiciales, calificar o no a una prestación de servicios como laboral, supone atraer hacia ella o excluir de ella una masa ingente de disposiciones en materia de condiciones de trabajo, individuales, colectivas -huelga, sindicación y negociación- y de protección y cargas sociales. Esta tesitura, que Martín Valverde ya vaticinaba en 1990 con cierta tendencia a la privatización de la contratación laboral ${ }^{7}$, hoy ha devenido -por mor de la crisis económica- en una masiva exclusión de prestaciones profesionales del campo de aplicación del Derecho del Trabajo y en un regreso a las tradicionales formas contractuales arrendaticias en las que la autonomía de la voluntad desempeña un papel preponderante y decisivo.

\section{EVOLUCIÓN HISTÓRICA}

Si se acepta que la relación entre hombres es la verdadera materia jurí$\mathrm{dica}^{8}$ y se repara en que el trabajo "fluye inesperadamente del hombre", posiblemente no parezca precipitado afirmar que el trabajo es el bien jurídico más idóneo para convertirse en objeto de negocio jurídico. Con todo, es lugar común entre los laboralistas calificar al Derecho Romano como una de las fases "prehistóricas" del Derecho del Trabajo ${ }^{10}$. En su opinión,

${ }^{6}$ Rodríguez-Piñero Royo y Calvo Gallego, Las relaciones laborales en los medios de comunicación, en Cruz VILLALón (editor), Trabajo subordinado y trabajo autónomo en la delimitación de las fronteras del Derecho del Trabajo. Estudios en homenaje al profesor José Cabrera Bazán (Madrid, 1999).

${ }^{7}$ Martín Valverde, El discreto retorno al arrendamiento de servicios, en Homenaje al Prof. Alonso Olea (Madrid, 1990) pp. 125 ss.

${ }^{8}$ Guasp, Derecho (Madrid, 1971), p. 13.

${ }^{9}$ Gierke, Las raíces del contrato de trabajo (traducción española de G. Barreiro, Madrid, 1982), p. 55.

${ }^{10}$ Véase, por todos: Alonso Olea, Introducción al Derecho del Trabajo (Madrid, 1987), p. 93. Bibliografía más reciente en: Alemán-Castán, Del trabajo como hecho social al contrato de trabajo como realidad normativa: un apunte histórico-romanistico (Madrid, 1997), p. XVI. Critica abiertamente la communis opinio laboralista GóMEz-Iglesias, La influencia del Derecho Romano en las modernas relaciones de trabajo (Madrid, 1995), p. 20 para el que las relaciones de trabajo no pueden tener más 
lo es así por faltar en ellas los rasgos que en la actualidad impregnan el tipo jurídico del contrato de trabajo en los ordenamientos positivos. Por tal razón, tales fases acaban siendo minusvaloradas para el iuslaboralista, relegadas a la anécdota, al dato sociológico, a la comparación somera e ilustrativa.

Como tendremos ocasión de desarrollar más adelante, la doctrina dominante en el ámbito iuslaboral retrotrae el nacimiento de la disciplina a la era del maquinismo, por entender que el trabajo característico de la sociedad industrial ha supuesto la introducción de nuevos principios jurídicos, distintos de los tradicionales del Derecho Civil, y es esta especialidad de principios la que ha provocado la emergencia de un derecho nuevo ${ }^{11}$. Lógico colorario de ello es el reputar lo anterior $-\mathrm{y}$ muy especialmente lo acaecido en Roma- como precedente remoto, olvidándose que no existe un tal distanciamiento ya que -como muy bien apuntan AlemánCastán ${ }^{12}$ - "no existe tal distanciamiento histórico ya que la construcción dogmático-civilística del contrato de arrendamiento de servicios tal como aparece regulado en las modernas codificaciones es pura y simplemente una traslación a tiempos no tan pretéritos de la locatio romana”. Empero, para Gierke ${ }^{13}$, el origen del contrato de servicios del ordenamiento alemán no es la locatio conductio romana sino una institución del Derecho Germánico, incluida en el derecho de personas: "el contrato de servicio fiel". Con todo, nosotros preferimos, por resultar más matizada, la tesis de Planitz, en cuya opinión, en el Derecho Germánico los contratos libres de trabajo, con eficacia exclusivamente jurídico-obligatoria, no aparecieron en lo esencial hasta la Edad Media. Sólo entonces es cuando surgen, con carácter típico, contratos en los que los trabajadores libres confieren sus energías de trabajo a cambio de una remuneración o compensación. En los dos contratos de trabajo más importantes, el contrato de servicio de criados ("Gesindevertrag") y el contrato de trabajo de oficiales y trabajadores ("Gesellenvertrag"), el trabajador es recibido en la comunidad doméstica del señor, quedando con ello sometido a su potestad. El desarrollo capitalista de fines de la Edad Media provocó un retroceso en la idea de la fidelidad y en la doctrina del Derecho Común triunfó la concepción romanista que

origen que las concepciones que genialmente han construido los juristas romanos.

${ }^{11}$ Basta con citar a título de ejemplo por tratarse del autor del manual más reiteradamente editado: Montoya Melgar, Derecho del Trabajo (22a edición, Madrid, 2001), pp. 42 ss.

${ }^{12}$ Alemán-Castán, Del trabajo como hecho social, cit. (n. 10), p. XVI.

${ }^{13}$ Gierke, Las raices, cit. (n. 9), p. 11 ss. Cabe advertir que aunque la traducción de Germán Barreiro es de 1982, el original alemán -Die Wurzeln des Diensvertrageses de 1914. 
equiparaba las energías de trabajo de las personas a los bienes susceptibles de derecho real, a las mercancías. Sin embargo, esta concepción exclusivamente jurídico-patrimonial del contrato de trabajo ha sido suprimida por el BGB., puesto que en él triunfan de nuevo las ideas del Derecho alemán elaboradas sobre el deber recíproco de fidelidad ${ }^{14}$. Así las cosas, a nuestro entender, estas particularidades germánicas que Gierke apunta y Planitz desarrolla -oscuras y poco fundadas en punto a sus orígenes y más claras por lo que hace a la regulación del contrato de trabajo en el B.G.B.pudieran explicarse por la tardía codificación civil alemana, que ve la luz casi un siglo después de la napoleónica ${ }^{15} \mathrm{y}$, por lo que se refiere a Alemania veinte años más tarde que la legislación bismarckiana sobre el contrato de trabajo $^{16}$. Ello, pues, no obsta en modo alguno, para considerar a la locatio conductio romana como el precedente más inmediato del contrato civil de arrendamiento de servicios.

La concepción del trabajo en la Antigüedad clásica es sobradamente conocida: tiene un sentido negativo. En este sentido, el arrendamiento de servicios (locatio conductio operarum) por virtud del cual una persona se obliga frente a otra a realizar ciertos servicios a cambio de una remuneración tiene una importancia secundaria en Derecho Romano ${ }^{17}$. La razón es doble: de una parte, sólo son susceptibles de ser arrendados los servicios de orden inferior, a los que se puede poner un precio que, por tanto, representa un valor patrimonial ${ }^{18}$, se excluyen, por el contrario, los servicios inestimables

${ }^{14}$ Planitz, Principios de Derecho Privado Germánico (traducción española de Melón Infante, Barcelona, 1957), p. 246.

${ }^{15}$ Sobre la polémica en torno a la codificación alemana, fruto del enfrentamiento entre la escuela filosófica y la escuela histórica, véase: ThiBAUT-SAvigny, La codificación (traducción española de Díaz García, Madrid, 1970). Más información al respecto en Rodríguez Ennes, Aproximación a la Historia Jurídica de Galicia (Santiago de Compostela, 1999), p. 183, n. 469.

${ }^{16}$ No deja de ser curioso que, juzgada con las convenciones de su momento, la idea de Bismarck de crear una organización de seguros estatales, fuese reputada de estrafalaria e imposible de poner en práctica [Cfr. Bismarck (traducción española de I. Hierro Madrid, 1999), p. 197]. De hecho aquella idea extraordinariamente ambiciosa de la organización de un sistema de seguros sociales benefició de forma extraordinaria a la clase trabajadora: el seguro de enfermedad se introdujo en 1883, el de accidentes en 1884 y el de invalidez y vejez en 1889 . No hubo en todo el mundo ninguna legislación social más progresista. Más información en GALL, Bismarck: The White Revolutionary (Londres, 1986). Para una visión más general, Fulbrook, Historia de Alemania (traducción española de B. G. Ríos, Cambridge, 1995), p. 182 ss.

${ }^{17}$ Daza- Rodríguez Ennes, Instituciones de Derecho Privado Romano (3a edición, Madrid, 2001), p. 384, con abundante bibliografía en pp. 413-414.

${ }^{18}$ Cicerón, ad. Att. 7,2,7, emplea el término operarius en un sentido decididamente negativo: "Illud tame de Chysipo: nam de altero illo minus sum admiratus, 
(operae liberales ${ }^{19}$ ) normalmente prestados gratuitamente por miembros de las clases sociales elevadas bajo la figura contractual del mandato ${ }^{20}$; partiendo de esta concepción, no tiene nada de extraño la consideración del trabajo asalariado como esclavitud temporal ${ }^{21}$. El segundo motivo de

operario homine". En realidad, el Arpinate consideraba a todas las operae, a excepción de la agricultura, sordidae e indignas de un hombre libre cuando eran ejercidas con ánimo de lucro. Sobre el pensamiento ciceroniano en este punto, cfr. Paladini, $C i$ cerone, en Revista Ciceroniana 1 (1959), p. 65-66. Séneca habla frecuentemente del motivo de la ausencia de nobleza en las artes manuales -artes quae manu constat- en las que no encuentra "nulla decoris, nulla simulatio" (Epist. 88, 21) y de la degradación social que acompañaba a su ejercicio. En Epist. 88, 22, califica de "labor sordidus et contumeliousus" a los negotia en general y estigmatiza a la ganancia con el apelativo de merces miserarum. El propio a. en Epist. 88, 20 llama viles en general a todas las artes "quae manu constant", mientras que tacha de sordida et vilissima a las ganancias correspondientes (mercedes). Para otros testimonios en el mismo sentido véase $\mathrm{DE}$ RoBerTis, Lavoro e lavoratori nel mondo romano (Bari, 1963), pp. 56 ss.

${ }^{19}$ La noción de studia liberalia es mucho menos amplia que el actual trabajo intelectual. Comúnmente se reputaban profesiones liberales, además de la de los oratores y advocati [a este respecto véanse: RoDRíguez ENNES, Reflexiones en torno al origen de los honorarios de los "advocati", en SDHI. 60-61 (1994-1995): Studi Romanistichi in memoria di Gabbio Lombardi, pp. 361 ss.; El MISMO, La remuneración de la oratoria forense: del rechazo inicial a su aceptación social y normativa, en Studi in memoria di Giambattista Impallomeni (Milano, 1999), p. 348 ss.]; las de los agrimensores, médicos, maestros y nodrizas [abundante literatura en BERNARD, La rémuneration das profesions liberáles en Droit romain classique (París, 1936), pp. 7-8]. Con todo, SÉNECA, Epist. 88,1, tras haber afirmado "liberalia studia sunt, quid homine libero digna sunt", especifica poco después que tal noción sólo comprende la filosofía a la que Quintiliano, Inst. orat. 12, 7, añade la gramática y la retórica.

${ }^{20}$ Nadie ha distinguido las operae de las artes liberales en términos tan netos como Cicerón; nadie mejor que él para traducir el desdén de la ciudad antigua por los trabajadores mercenarios: véase, por ejemplo, De off. 1,42,150-151. Sobre las fuentes ciceronianas en este pasaje y sus relaciones con el pensamiento de Panecio, véase: Labowsky, Die Etik des Panaitos (Leipzig, 1933), p. 676; Fhilippson; Das Sittlischöne bei Panaitos, en Philologus (1955), p. 357; de donde se infiere que el Arpinate se limita a retomar una distinción conocida desde tiempo atrás y mantenida en la Antigüedad. Aristóteles la había dejado plasmada en sus escritos (Polit. 3,5, 1278a; 3,4, 1277a; 5,7, 1234a; Rethor. 1,9, 13676a; Séneca, De Benef. 3,22, hará suyas las palabras de Crisipo declarando que el esclavo es un mercenario a perpetuidad: "Servus ut placet Chrysippo perpetuum mercenarius est".

${ }^{21}$ Zeitliche Sklaverei; cfr. ERdmann, Frei Berufe und Arbeitsuerträge in Rom, en Zeitschrift der Savigny-Stiftung 79 (1948), p. 567, el calificativo de ingenuae que se les asignaba, se explica paladinamente por el hecho de que cuando tales tareas eran ejercidas por esclavos, dejaban de ser consideradas como artes liberales. En este sentido, en Cicerón se encuentran emparejados "liberalis et ingenuus: homines ingenui et liberaliter educati. (De fin. 3, 17, 57); "liberalis doctrinae atque ingenuae" (De orat. 3, 22, 127); así: "ingenuae atque humanae artes" (ibid. 3, 6, 21), artes elegantes et 
la exigua importancia del arrendamiento de servicios radica en la gran amplitud que tuvo en Roma el trabajo de los esclavos ${ }^{22}$.

En efecto, la concepción social del trabajo y su protección jurídica, que caracterizan al Estado moderno y sus fines, eran desconocidas totalmente en la sociedad antigua ${ }^{23}$. El Derecho Romano de arrendamiento respondía naturalmente a las condiciones sociales y económicas de la época. Las partes contratantes fueron perfectamente libres de celebrar el contrato, de configurarlo como les pluguiese, lo cual significa, naturalmente, que el contrato era del tenor que placía al patrono. Así las cosas, tal situación de notoria y flagrante desigualdad contractual se mantuvo impávida hasta el último tercio del siglo XIX. Mas, desgraciadamente, nuestro mundo - pese a los notorios avances científicos- mutó parcamente en el ámbito de la justicia social a lo largo del Medievo y del Antiguo Régimen. Y, de manera asombrosa, en nuestros días, iniciado ya el tercer milenio, la catástrofe económica nos está conduciendo inexorablemente a la situación que provocó la llamada "cuestión social" en los albores de la Revolución Industrial. Todo ello vuelve a situarnos en un contexto que Schulz era incapaz, por inimaginable, de predecir en los años cincuenta del pasado siglo ${ }^{24}$.

ingenuae (De fin. 3, 1, 4); ingenuae studiis atque artibus delectari (ibid. 5, 18, 48). En Séneca se halla: "liberalia studia et artes liberalia" (Epist. 88, 1, 18-20); además, Séneca opondrá las "viles ex professo artes quae manu constant [...] in quibus nulla decoris, nulla honesti simulatio est" (ibid. 17 y 21). Sería fácil multiplicar las citas, cfr. LöWENFELD, Inästabilität und Honorarung des artes liberales nach röm. Recht, en Festgabe Plank (Munich, 1887), pp. 370 ss.; más modernamente: RodríGuez EnNes, La remuneración de la oratoria forense, cit. (n. 19), pp. 348 ss.

${ }^{22}$ Como es sabido, si la guerra fue la fuente esencial de la esclavitud, la Segunda Guerra Púnica marca el comienzo de la serie de grandes guerras de conquista que abastecieron los mercados romanos de enormes contingentes de esclavos. En total, si aceptamos las estimaciones de Staerman, Die Blutezeit der Sklavenwirtschaft in der römischen Republik (Wiesbaden, 1969), pp. 43-44, hubo 463.310 esclavos para el período del 218 al 88 a. C., a los que hay que añadir los esclavos de nacimiento. Además y con referencia a épocas posteriores, existen datos que constatan que sólo César en diez años de campaña en las Galias hizo cientos de miles de cautivos (Veleyo PAtérCulo, 2, 47: "Per haec insequentiaque et quae praediximus tempora amplius quadringenta milia hostium a C. Caesare caesa sunt, plura capta"; y Estrabón, 14, 5, 2 estima en 10.000 los esclavos que diariamente se vendían en el mercado de Delos. En estas condiciones no es extraño que el número de libertos no cesara de aumentar; Tregiari, Roman Freedmen During the Late Republic (Oxford, 1969), p. 36, estima que en Roma y en las ciudades vecinas el número de libertos era superior al de los ingenui.

${ }^{23}$ Véase, al respecto, VV. AA., Las formas de explotación del trabajo y relaciones sociales en la Antigüedad clásica (traducción española de J. Calatrava, Madrid, 1979).

${ }^{24}$ Schulz, Derecho romano clásico (traducción española de Santa Cruz Teijeiro, Barcelona, 1960), pp. 520-521, aseveraba la impresión de pobreza que produce el 


\section{LA INSUFICIENCIA DEL DERECHO COMÚN Y EL NACIMIENTO DE LA "CUESTIÓN SOCIAL"}

Es de sobra conocido que el nacimiento de las relaciones laborales en sentido propio coincide con el advenimiento de la revolución industrial y, lo que es más importante, con el triunfo de las ideas liberales que si en el plano político supusieron la eliminación de las corporaciones intermedias entre el individuo y el Estado y en el económico la sustitución del proteccionismo colbertista por el orden natural de los fisiócratas (encerrado en la máxima laissez faire laissez passer) en el orden jurídico, como con frecuencia se ha repetido, supusieron la instauración del dogma de la autonomía de la voluntad. En la Época Contemporánea se observa con acusado relieve la disociación entre los sistemas ideológicos y las estructuras políticas, económicas, sociales y jurídicas en que aquellos encuentran o tratan de alcanzar realización. Así, el credo liberal e individualista, formulado inicialmente en los mismos comienzos de la edad anterior, obtiene ahora su consolidación (o "consagración", según la terminología entonces en boga) al consagrarse solemnemente en los grandes códigos del siglo XIX; pero, a la vez, cuando este triunfo se consigue, muchas de las normas $y$, por tanto, muchas de las ideas que las legitimaban están ya muertas o en vías de fosilización ${ }^{25}$. El Derecho triunfante es, así, anacrónico y, lo que es más grave, en atención a su falta de adecuación con la realidad social que tenía que regular, puede ser considerado como injusto.

Este divorcio radical entre el régimen jurídico de signo individualista y liberal del XIX y las estructuras socio-económicas, se muestra especialmente patente en España debido al evidente retraso de nuestra codificación privada ${ }^{26}$, relegada a fines de siglo cuando ya habían tenido lugar las grandes convulsiones mundiales de 1848 y de $1871 \mathrm{y}$, en especial, tras la catarsis nacional de 1868 a 1874 . Tomás y Valiente ha señalado que

derecho clásico de arrendamiento si se le compara con el moderno, pero se precisaba tener en cuenta, a su juicio, que las condiciones socio-económicas de Roma diferían grandemente de las actuales; de ahí que el problema actual del Derecho del Trabajo no pudiera plantearse entonces. Lejos estaba el ilustre romanista alemán de que cincuenta años después asistiríamos a un masivo encuadramiento de la relación laboral en los viejos esquemas de la locatio conductio, tan denostada por él.

${ }^{25}$ Borrajo, Introducción al Derecho del Trabajo (8a edición, Madrid, 1995), p. 76.

${ }^{26}$ Acerca del retraso que supuso en nuestro proceso codificador el fracaso del proyecto isabelino, véase, Rodríguez Ennes, Influencia del Proyecto de 1851 en los códigos Iberoamericanos, en Actas del II Congreso Internacional y V Iberoamericano de Derecho Romano (Madrid, 2001), pp. 257 ss. 
la codificación civil española fue la "larga historia de una frustración" 27. Sin duda fue una larga marcha, un proceso que parecía no llegar a su fin. Una sociedad burguesa con Constitución, pero sin Código Civil era una sociedad incompleta, coja, mal construida. El mismo autor ha declarado que el Código Civil no se hizo antes "porque cuando se quiso no se supo y cuando se supo no se quiso"28. A diferencia de lo sucedido en Francia, donde el Code Napoléon precedió a los demás, el Código Civil no sólo no abrió en España el proceso codificador, sino que constituyó su último capítulo. Es así ciertamente curioso que aquí llegara a codificarse antes el Derecho adjetivo o procesal civil, que el sustantivo al que aquél debería adaptarse. Retraso todavía más grave aún si tenemos en cuenta que nuestros ilustrados sintieron vivamente el ideal codificador desde el siglo XVIII ${ }^{29}$. Tal anomalía suele ser explicada por varias causas. El no haber alcanzado y consolidado los principios sobre los que se apoya la revolución liberal (el derecho de propiedad y las libertades fundamentales de la persona) ocupa un lugar prevalente ${ }^{30}$; la cuestión, indudablemente muy sugestiva sobrepasa el tema de nuestro estudio; empero siempre quedará la duda de por qué triunfó el Code Civil, apenas iniciada la paz burguesa o los Códigos italiano de 1865 o portugués de 1867 en países con tantos residuos al menos como el nuestro del orden feudal. Así las cosas, un Derecho que,

\footnotetext{
${ }^{27}$ Tomás y Valiente, Manual de Historia del Derecho Español (Madrid, 1983), p. 536.

${ }^{28}$ Tomás y Valiente, Códigos y Constituciones. 1808-1978 (Madrid, 1989), p. 26.

${ }^{29}$ En este sentido, De Castro, Federico, Derecho Civil de España (Madrid, 1955), I, p. 194, escribe: "El ideal codificador se hará sentir especialmente en la Espańa del siglo XVIII; está en los proyectos de Ensenada, en el antirromanismo de Macanaz, en la petición de leyes derivadas de principios nacionales de Jovellanos y en todo el deseo reformista del Setecientos".

${ }^{30} \mathrm{El}$ interesante trabajo de Maluquer de Motes, La codificación civil en España, sintesis de un proceso, en Revista de Derecho Privado (1981), pp. 1083-1101, está dedicado a probar que la codificación es el resultado final de un largo proceso, que no podría cerrarse hasta haber obtenido la total transformación de la propiedad y haber alcanzado el conjunto de los derechos individuales. Es menester la transformación de la propiedad de la tierra, que pierda sus elementos feudales y se haga libre, absoluta e individual, una vez desvinculada y desamortizada; que se despatrimonialicen las propiedades especiales (v. gr. aguas) y se consolide la propiedad adquirida (en particular el dominio de los inmuebles mediante la institución del Registro de la Propiedad); que se reconozcan las libertades individuales proclamadas por la Revolución liberal de 1868; una vez desarrollada la Constitución de 1869, y si la Codificación y Constitución no pueden llevar un rumbo distinto, la Codificación se alcanzará con las transformaciones de la propiedad en la esfera de la sociedad y de los derechos de la persona en la esfera individual.
} 
a fines del diecinueve, reducía la regulación de las relaciones del capital y del trabajo al libre juego de la voluntad autónoma de las partes, más que dar solución al problema venía a radicalizarlo y, por tanto, podía calificarse como no existente.

La insuficiencia del Derecho Común para dar respuesta a la llamada "cuestión social" se presenta como la causa principal de la emergencia de un contrato de trabajo diferenciado del clásico arrendamiento de servicios ${ }^{31}$. Tal especialidad, en decir de Borrajo ${ }^{32}$, aparece cuando la aplicación de la norma de Derecho Común que debía garantizar la paz social en el orden laboral, dio lugar a un problema tan grave que ha pasado a la Historia como la "cuestión social" por antonomasia: la cuestión obrera. Gráficamente ha dicho Casas Baamonde, que: "el Derecho del Trabajo hubo de nacer y desarrollarse contra el Derecho Civil o Común" ${ }^{33}$ y, como con acierto opina Giugni: "El Derecho del Trabajo, en el aspecto que concierne al contrato de trabajo, constituye un sistema de límites a la autonomía privada" ${ }^{4}$. El Derecho Civil queda, pues, definitivamente rezagado en la comprensión de la institución del nuevo orden jurídico -el contrato de trabajo- tanto como en el entendimiento de su fuente peculiar -el convenio colectivo de condiciones de trabajo-. Radbruch ha percibido y descrito muy exac-

${ }^{31}$ La doctrina se ha ocupado de esta insuficiencia del Derecho Civil para atender los problemas suscitados por la cuestión social con un detenimiento tal que excusa ahora de cualquier alusión que exceda de la mera cita de autores. Entre los primeros estudiosos del Derecho Social, destacan De Aguinaga Tellería, Derecho del Trabajo (Madrid, 1952), pp. 24 ss.; Hernainz Márquez, Tratado Elemental de Derecho del Trabajo (7a Edición, Madrid, 1955), pp. 7 ss.; Martín Granizo-González Rothvoss, Derecho Social (3a edición Madrid, 1935), pp. 12 ss.; Callejo De La Cuesta, Derecho Social (Madrid, 1935), p. 49. Entre los modernos laboralistas, además de los manuales ya citados en notas anteriores, cabe mencionar a: MARTín VALVERDE, La formación del Derecho del Trabajo en España, en VV. AA. La legislación social en la Historia de España. De la revolución liberal a 1936 (Madrid, 1987), p. XI ss.; Montoya Melgar, Ideología y lenguaje en las primeras leyes laborales (Madrid, 1975); El MISMO, Ideología y lenguaje en las leyes laborales de España: la crisis de 19171923 (Murcia, 1977); El mismo, Ideología y lenguaje en las leyes laborales de España: la dictadura de Primo de Rivera (Murcia, 1980); El mismo, Ideología y lenguaje en las leyes laborales de la Segunda República (Murcia, 1983)]; Alonso Olea, Las raíces del contrato de trabajo, en Anales de la Real Academia de Jurisprudencia y Legislación 21 (1989), pp. 339 ss.; Diéguez Cuervo, Derecho y trabajo (Madrid, 1963), pp. 22 ss.; Palomeque, Derecho del Trabajo e ideología (3a edición, Madrid, 1987), pp. 15 ss.

${ }^{32}$ Borrajo, Introducción, cit. (n. 25), pp. 38-39.

${ }^{33}$ Casas BAAmonde, La individualización de las relaciones laborales, en Relaciones Laborales (1991), II, p. 405.

${ }^{34}$ Giugni, Derecho del Trabajo. Voz para una enciclopedia, en Temas Laborales 13 (1987), p. 58. 
tamente el fenómeno de la insuficiencia del Derecho Civil para regular el trabajo generalizado en la sociedad contemporánea: "El Derecho obrero constituye una reacción contra el espíritu del Derecho Civil. Éste reconoce sólo personas, sujetos jurídicos iguales por ambas partes; y nada sabe del trabajador situado en inferioridad frente al empresario. Nada sabe tampoco de la solidaridad del proletariado que compensa o nivela esta inferioridad del poder del empresario individual frente al patrono, ni de las grandes asociaciones profesionales [...]. Nada sabe, por fin, de la unidad de asociación en la empresa; el Código Civil considera sólo una multiplicidad de contratos de trabajo entre el mismo empresario y los diversos obreros, y no acierta a ver la índole de la empresa, como una unidad sociológica cerrada" ${ }^{35}$. Así surge, con perfiles claramente diferenciados frente al Derecho Civil, el Derecho del Trabajo.

En este sentido, es claro que la aparición del Derecho del Trabajo es el resultado de la tensión entre dos fuerzas contrarias, la que encarna la libertad individual -tal como se entiende en el siglo XIX-y la que se le opone para compensar el desequilibrio existente en las relaciones entre empresarios y trabajadores: la intervención de los poderes públicos en la vida social que, a fin de cuentas, no es sino la constatación de esa característica común en todas las sociedades que resalta Kahn Freund, la "desigual distribución del poder" que la ideología liberal pretendió enmascarar bajo la pantalla del contrato, teóricamente concebido como un acuerdo entre iguales $^{36}$. Con ello se exterioriza una primera tensión, la que enfrenta la autonomía del individuo y la heteronomía del Estado; en el fondo lo que se está afirmando es la libertad de trabajo frente a una peligrosa constatación de la libertad de contratación ${ }^{37}$.

Las sucesivas leyes obreras que paulatinamente se promulgan como respuestas de los Estados a las crecientes reivindicaciones sociales constituyen, pues, el germen del Derecho laboral, aunque éste no aparece en propiedad hasta que se regula de forma autónoma el contrato de trabajo, hecho éste que, en nuestro país, fue preparado por la aparición del Código

${ }^{35}$ RadBruch, Einfürung in die Rechtwissenschaft (Leipzig, 1925), pp. 153-154.

${ }^{36}$ Kahn Freund, Trabajo y Derecho (traducción española de J. M. Galiana, Madrid, 1987), cap. I, passim. Afirmaciones con claros antecedentes en Renner, The Institutions of Private Law and their Social Functions (Londres, 1949), p. 141, con introducción a cargo del propio Kahn Freund.

${ }^{37}$ Cfr. W. Friedmann, Legal Theory (5a edición, Londres, 1967), p. 401, donde afirma: "Originally freedom of contract represented the emancipation of labour from the fetters of status; but as freedom of contract, owing to the inequality of bargaining position, came into conflict with freedom of labour, the law more and more emphaisized the latter if necessary, at the expense of the former". 
de Trabajo de 1926 e iniciado con la promulgación de la primera Ley de contrato de trabajo, de 21 de noviembre de 1931. Hasta ese momento el llamado "contrato de trabajo" era sólo el resultado de la proyección sobre los contratos de arrendamientos regulados en el Código Civil de las normas contenidas en la legislación industrial ${ }^{38}$. Normas, como se sabe, de carácter administrativo y de policía con fines principalmente tutelares. En ningún momento llega a diferenciarse con nitidez un contrato de trabajo distinto del contrato de arrendamiento de servicios, sino que ambos aparecen confundidos. Así lo prueba la Ley de tribunales industriales, de 19 de agosto de 1908, cuyo artículo 5, al fijar su competencia declaró que dichos tribunales conocerían: "De las reclamaciones civiles que surjan entre patronos y obreros o entre obreros del mismo patrono, sobre incumplimiento o rescisión de los contratos de arrendamiento de servicios, de los contratos de trabajo o de los de aprendizaje".

Este proceso de "laboralización" del arrendamiento no es sino, como hemos dicho, el resultado coherente de la inadecuación de los moldes individualistas del Derecho Civil para adaptarse a las nuevas relaciones entre empresarios y trabajadores. Inadecuación que ya denunciaba con toda claridad el preámbulo de la Real Orden de 9 de noviembre de 1902, cuando recomendaba la reforma del Código Civil en materia de arrendamiento de servicios, afirmando que el que ya llamaba contrato de trabajo "se refiere a relaciones intimamente ligadas con las cuestiones sociales, que tanto han preocupado siempre, y hoy más que nunca preocupan a todos los gobiernos", por lo que para su regulación no basta "la aplicación de los principios generales en que se basan las obligacione" 39 .

El proceso español de especificación del contrato de trabajo discurre -al igual que en el resto del continente europeo- por los cauces legislativos comunes a los países de Derecho Civil, aunque con fluctuaciones importantes, pues si en un principio la Real Orden de 1902, a la que acabamos de referirnos, aconsejó la modificación de los artículos del Código Civil que aún hoy regulan el arrendamiento de servicios, la larga serie de proyectos que se suceden a partir de 1904 se dirigen, por el contrario, a la elaboración de una ley especial que regulará el contrato de trabajo o arrendamiento laboral de servicios, cuya primera regulación unitaria se alcanza en nuestro país, como es sabido, bajo forma codificada -el Código de Trabajo de la dictadura de Primo de Rivera- para posteriormente durante la República y la Era de Franco derivar hacia Leyes de Contrato de Trabajo o de Rela-

${ }^{38}$ Luján Alcaraz, La contratación privada de servicios y el contrato de trabajo (Madrid, 1994), p. 31.

${ }^{39} \mathrm{Cfr}$. su texto en: Información legislativa española y extranjera sobre contrato de trabajo (Madrid, Instituto de Reformas Sociales, 1921), p. 10. 
ciones Laborales que, en la actual fase democrática, se sustituyen por un reiteradamente reformado Estatuto de los Trabajadores ${ }^{40}$.

En el sistema inglés del "Common Law", el proceso de laboralización del arrendamiento de servicios va a discurrir por cauces esencialmente diferentes. Al ser Inglaterra un país que resiste incólume el embate codificador $^{41}$, unido a las peculiaridades de sus sistema jurídico, el contrato de trabajo permanecerá anclado al molde individualista del derecho general de los contratos y las limitaciones más importantes a la autonomía de la voluntad no tendrán su base más sólida en la intervención parlamentaria; en el esquema jurídico inglés, caracterizado tradicionalmente por un notable abstencionismo del Derecho, el modelo contractual sobre el que se asientan las relaciones entre "employer" y "employee" seguirá siendo el mismo que sirvió de nexo a las relaciones entre master y servant. Las correcciones se impondrán básicamente por la poderosa influencia de las “trades unions”, limitándose al intervencionismo legislativo, al menos inicialmente, a la defensa de sectores marginados de la contratación colectiva o, en su caso, a la corrección de posiciones del "Common Law", que se juzgan insostenibles. Inglaterra conservará, pues, el sistema liberal del "laissez faire", aunque desgajado de sus orígenes individualistas para transformarse en lo que Kahn Freund denominara un "laissez faire", colectivo ${ }^{42}$.

Si la figura del arrendamiento de servicios fue derivando hacia la noción autonómica del contrato de trabajo por obra de la intervención legislativa, no hay que perder de vista que la organización progresiva de las clases trabajadoras va paulatinamente exigiendo una participación en el poder social que implica la adquisición por los grupos laborales de una cierta autonomía frente al ordenamiento estatal. Se reproduce así la tensión autonomía-heteronomía, pero el centro de gravedad experimenta un desplazamiento apreciable. Ya no se trata de que el individuo -ese ser "profundamente aislado, en una terrible soledad social" de que hablara Bayón Chacón ${ }^{43}-$, demande la protección de las leyes estatales; ahora son colectividades organizadas que exigen una participación en el poder

${ }^{40}$ Galiana Moreno, Crisis del contrato de trabajo, en Revista de derecho social 2 (1998), p. 51.

${ }^{41}$ Sobre las peculiaridades del sistema anglosajón, véase: Rodríguez EnNEs, $L a$ recepción del Derecho Romano en Inglaterra, en Actas del I Congreso Iberoamericano de Derecho Romano (Granada, 1997), pp. 203 ss., con bibliografía.

${ }^{42}$ Kahn Freund, Legal Development. Labour Law, en Law and Opinion in England in the 20 th Century (London, 1959), p. 224; luego incluida en Selected Writings (London, 1978), p. 8, cito por esta última.

${ }^{43}$ Bayón Chacón, La autonomía de la voluntad en el Derecho del Trabajo. Limitaciones a la libertad contractual en el Derecho histórico español (Madrid, 1955), p. 267. 
social. Lo que se cuestiona es la exclusividad normativa del Estado en el mundo del trabajo; lo que se expresa es la inadecuación de las leyes para resolver el problema obrero; lo que se reclama, en fin, es la configuración de un nuevo orden normativo. Consecuencia clara de este proceso de intervencionismo estatal, al que sin duda hay que añadir la importancia notoria de la negociación colectiva como vía de fijación del contenido del contrato, éste se ha visto privado de su primitivo carácter regulador; la autonomía individual (la lex contractus) ha sido en buena parte suplantada por la regulación heterónoma, desde fuentes externas, que ha hecho que el contrato de trabajo se haya limitado a ser la llave que abre la puerta a la relación laboral, pero no el instrumento esencialmente regulador de la misma $^{44}$.

\section{CRISIS DEL DERECHO LABORAL CLÁSICO \\ Y VUELTA A LAS TRADICIONALES FIGURAS ARRENDATICIAS}

Hoy en día, con la "crisis occidental", los nuevos principios neoliberales (flexibilización, desregulación, etc.) están informando una legislación excepcional del trabajo; es decir, aparecen unas leyes laborales que se desvían del conjunto sistemático regulador de las relaciones de trabajo; son la "excepción" dentro del régimen laboral anterior, por lo que reaparece la tensión entre lo nuevo y lo tradicional, entre lo excepcional y lo común laborales ${ }^{45}$. Si se extienden los nuevos principios y las normas de coyuntura se consolidan y hacen permanentes, es posible que las nuevas estructuras normativas obliguen a una revisión contractual profunda del Derecho del Trabajo. De ahí que nos guste decir que el Derecho laboral de la crisis puede ser la crisis del Derecho laboral clásico. El nuevo Derecho laboral se "civiliza" o "mercantiliza" con su espíritu economicista, por lo que se tiende a perder su especialidad y a integrarse en el Derecho común.

En este sentido se habla de "deslaboralización" 46 como proceso de

\footnotetext{
${ }^{44}$ Recuérdese, en este sentido, la reiterada afirmación de Montoya Melgar en las sucesivas ediciones -hasta el momento 28- de su Derecho del Trabajo, en orden a que es función del contrato de trabajo dar ocasión a la aplicación automática de las normas estatales y colectivas [Cfr. la $28^{\mathrm{a}}$ ed. (Madrid, 2007), p. 267].

${ }^{45}$ Véase, por todos: Blasco Pellicer, La individualización de las relaciones laborales (Madrid, 1995); SAgardoy Bengoechea, La libertad sindical y los espacios de la autonomía privada, en Debate Laboral 24 (1988), pp. 8 ss.; D’Antona (editor), Politiche di flessibilitá e mutamenti del Diritto del Lavoro. Italia e Spagna (Napoli, 1990); Simitis, Diritto del Lavoro e la riscopera del individuo, en Giornale di Diritto del Lavoro e di Relazioni Industriali 45 (1990), pp. 87 ss.; Casas BaAmonde, La individualización, cit. (n. 33), p. 402-403.

46 "Brutto neologismo" para Romagnoli, Arriva un bastimento carico di A, en
} 
exclusión del sistema de tutelas jurídico-laboral y su sustitución por otro complejo de reglas de progenie privatística. La extensión y desarrollo de la precariedad laboral, el recurso generalizado a la contratación temporal como fórmula casi exclusiva de inserción laboral, la legalización de empresas interpuestas en el mercado de trabajo con el objeto de ceder trabajadores temporales a otras empresas usuarias y la reducción de determinados contratos formativos en mecanismos de empleo con bajos costes sociales, es una seña de identidad de la nueva regulación del trabajo, que cobra especial relieve en ordenamientos como el español y que produce la debilitación del sistema de garantías y del contenido de la protección para un importante segmento de trabajadores ${ }^{47}$. Este mercado retorno al "individualismo" y a la "desregulación" de las relaciones de trabajo ha provocado amplias cotas de temporalidad en la contratación y, como consecuencia de ello, elevadas dosis de precariedad en el empleo a las que se ha tratado de poner coto en nuestro país a partir de 1999 y, todo hay que decirlo, con escaso éxito pese a la acusada proliferación legislativa ${ }^{48}$.

D’Antona (editor), cit. (n. 46), p. 32.

${ }^{47}$ Ortiz Lallana, La transformación del Derecho del Trabajo ante los nuevos retos sociales (Lección inaugural del curso académico 1999-2000, Universidad de La Rioja, 1999), pp. 14-15.

${ }^{48}$ Como precedentes más inmediatos de la Reforma de 1994, pueden citarse el RDL. 19/1993, de 3 de diciembre, de medidas urgentes de fomento de la ocupación y la Ley No 22/1993, de 29 de diciembre, de medidas fiscales, de reforma del régimen jurídico de la función pública y de protección por desempleo [sobre ellas, véase: Palomeque-Cabero, Todo sobre las primeras normas de Reforma del Mercado de Trabajo (Barcelona, 1994)]. No obstante, la reforma estuvo básicamente integrada por la Ley No 10/1994, de 19 de mayo, sobre medidas urgentes de fomento de la ocupación; la Ley No 11/1994, de 19 de mayo, por la que se modifican determinados artículos del Estatuto de los Trabajadores, del Texto Articulado de la Ley de Procedimiento Laboral y de la Ley sobre Infracciones y Sanciones del Orden Social, y la Ley No $14 / 1999$, de 1 de junio, por la que se regulan las empresas de trabajo temporal y que incluye la disposición adicional cuarta a la Ley Orgánica No 11/1985, de 2 de agosto, de libertad sindical (sobre ellas, sin ánimo exhaustivo, por todos, puede verse Sala Franco, La Reforma del Mercado de Trabajo (Valencia, 1994); VAldÉs DAL Re (editor) La Reforma del Mercado Laboral (Valladolid, 1994); VV. AA., Estudios de Jurisprudencia. Análisis de los aspectos básicos de la Reforma del ET y de la LPL, en Colex 11 (1994); Escudero Rodríguez (editor) Reforma de la Legislación Laboral (Sevilla, 1997); VV. AA. El trabajo ante el cambio de siglo: un tratamiento multidisciplinar (Madrid, 2000). En 1997 tuvo lugar la Reforma laboral originada por el Pacto laboral para el empleo entre las organizaciones empresariales y sindicales más representativas. Fruto del mismo fueron dos Reales Decretos Leyes, ambos de 16 de mayo, de medidas urgentes para la mejora del mercado de trabajo y el fomento de la contratación indefinida y el RDL. No 9/1997, por el que se regularon incentivos en materia de Seguridad Social y de carácter fiscal para el fomento de la contratación 
Si se asume la expresión de la "huida" del Derecho del Trabajo, ésta, principalmente, se produciría hacia el Derecho Civil o Mercantil ${ }^{49}$. El desplazamiento o "contracción" 50 del Derecho laboral hacia formas civiles o mercantiles es quizá el fenómeno más conocido y frecuente en los estudios laboralistas. La prestación de servicios se encuadra en el arrendamiento de servicios civil o en contratos mercantiles como los de transporte, suministro, etc. El supuesto base que subyace a la elección de estos contratos distintos del laboral suele consistir en nuevas profesiones o nuevos servicios respecto de las clásicas estructuras ocupacionales, como sucede con los mensajeros $^{51}$, los encuestadores ${ }^{52}$ o los guías turísticos ${ }^{53}$, por poner sólo algunos ejemplos, o bien en nuevas formas de prestar el trabajo, como típicamente se aprecia en el teletrabajo ${ }^{54} \mathrm{o}$, en fin, en las nuevas formas

indefinida y del fomento del empleo, ambos RR.DD.LL fueron convalidados por el Congreso de los Diputados y su tramitación como sendos proyectos de ley culminó con la Ley No 63/1997, de 26 de diciembre de medidas urgentes para la mejora del mercado de trabajo y el fomento de la contratación indefinida y la estabilidad en el empleo. Sobre ellas, también sin ánimo exhaustivo, véase: Albiol Montesinos y otros, La Reforma Laboral de 1997 (2a edición, Valencia, 1998); Rojo Torrecilla (editor) Las Reformas Laborales de 1994 y 1997 (Madrid, 1998). No obstante, es una reforma inacabada. La tendencia reformadora continua y muestra de ello es, entre otros, el RDL No 15/1998, de 27 de noviembre, de medidas urgentes para la mejora del mercado de trabajo en relación con el trabajo a tiempo parcial y el fomento de su estabilidad o el RD. No 2720/1998, de 18 de diciembre, por el que se desarrolla el artículo 15 del Estatuto de los Trabajadores en materia de contratos de duración determinada o la Ley No 29/1999, de 16 de julio, de modificación de la Ley No 14/1994, de 1 de junio, por la que se regulan las empresas de trabajo temporal. A mayor abundamiento debemos constatar el RDL. No 5/2001 de Medidas Urgentes de Reforma del Mercado de Trabajo.

${ }^{49}$ Rodríguez-Piñero, La voluntad de las partes en la calificación del contrato de trabajo, en Relaciones Labores. Revista Crítica de Teoría y Práctica 18 (1996), p. 3, es quien ha acuñado por primera vez esta expresión al referirse a los mecanismos de huida del Derecho del trabajo y de sus costes sociales.

50 Tendencia contractiva o de fuga, la denomina López Gandía, Contrato de trabajo y figuras afines (Valencia, 1999), p. 11.

${ }^{51}$ Objeto de extenso debate doctrinal a partir de la declaración de laboralidad de los mismos por el Tribunal Supremo en dos sentencias de 1986. Así, Escudero Rodríguez, Sobre la laboralidad de los mensajeros, en La Ley 4 (1996), pp. 795 ss.; Valdés-Pedrajas, Contrato de transporte, ¿un giro en la jurisprudencia?, en Documentación Laboral 19 (1986), pp. 97 ss.

${ }^{52}$ Declarada también su relación laboral en sentencias de 1992 y 1994, cfr. CHACARATEGUI, ¿Los encuestadores son trabajadores? (Madrid, 1996).

${ }^{53}$ López-Gandía, Contrato de trabajo, cit. (n. 50), pp. 57-59.

${ }^{54}$ Gallardo Moya, Viejo y nuevo trabajo a domicilio. De la máquina de hilar al ordenador (Madrid, 1998). 
de organizar la producción a través de la externalización de servicios, que permite la conclusión de contratos de transporte, de suministros o de figuras como la franquicia ${ }^{55}$, pero se extiende un poco uniformemente a las diversas figuras profesionales que clásicamente se han ejercido en términos de independencia como es el caso de las profesiones liberales. La historia de estos procesos de deslaboralización ha estado jalonada de una serie de pronunciamientos jurisprudenciales, que respondían así al cuestionamiento de este tipo de fórmulas de inserción no laboral.

Paralelamente, desde hace algunos años se vienen produciendo lo que doctrinalmente se ha denominado una "crisis de autoridad" de las fuentes externas de fijación de condiciones de trabajo "tanto en su expresión legal como colectiva" ${ }^{\prime 6}$. Se quiere indicar con ello que cada vez se va extendiendo con más fuerza "una visión recuperadora de la autonomía individual y del contrato como expresión máxima de ésta”; posición que en última instancia tiende a "robustecer las potencialidades del libre acuerdo de voluntades en la regulación de las condiciones de trabajo" ${ }^{57}$. En este sentido, habría que indicar que la tensión constante entre autonomía-heteronomía sufre un giro de signo inverso al que históricamente ha caracterizado el proceso de consolidación del Derecho del Trabajo; o, dicho de otra manera, el proceso de individualización de las relaciones laborales nos retrotrae a los comienzos del ordenamiento laboral ${ }^{58}$. Si, como hemos venido indicando, tanto la intervención del Estado como la de los grupos profesionales en la fijación de condiciones de trabajo han desposeído al contrato de su carácter regulador como medio de compensar el desequilibrio que subyace en las relaciones laborales, en cuanto relaciones de subordinación, hoy se nos lanza el mensaje que es preciso "restituir al trabajador una libertad de la que ha sido demasiado frecuentemente explotado por la heteronomía y la colectivización" ${ }^{59}$. Con este punto de partida, en los últimos años se viene produciendo un doble tipo de actuaciones. Por un lado las reformas laborales más recientes han supuesto un desplazamiento del punto de

${ }^{55}$ González Biedma, Aspectos juridico-laborales de las franquicias, en Revista Española de Derecho del Trabajo 97 (1999), pp. 670-671.

${ }^{56}$ OJedA, Autonomía colectiva y autonomía individual, en Relaciones Labores. Revista Crítica de Teoría y Práctica 2 (1991), p. 67.

${ }^{57}$ Baylos, Derecho del Trabajo modelo para armar (Madrid, 1991), p. 67,

${ }^{58}$ Cfr. Smitis, en $5^{\text {th }}$ European Regional Congress for Labour Law and Social Security (Leiden, 1966), p. 17, de forma tajante indica: "In short, individualisation brings us back to the beginnings of eployement law, en Is there still a future for employment law?".

59 Tal es la opción cultural subyacente que, con referencia a la realidad italiana denuncia D'antona, La autonomía individual y las fuentes del Derecho del Trabajo, en Relaciones Labores. Revista Crítica de Teoría y Práctica 2 (1991), p. 286. 
equilibrio entre ley convenio colectivo, esto es entre heteronomía estatal y autonomía colectiva. Normas que en el pasado constituyeron auténticos bastiones de lo que se viene denominando derecho necesario o imperativo se han visto desposeídas de tal carácter para pasar a ser disponibles por la autonomía negocial ${ }^{60}$. Por otro, la tendencia creciente de retorno al contrato se manifiesta asimismo, y de manera especial, en el terreno de las relaciones entre autonomía individual y autonomía colectiva, especialmente en la reacción suscitada contra la fijación uniforme de condiciones de trabajo mediante la negociación colectiva, lo que plantea conflictos entre el contrato individual y el convenio colectivo ${ }^{61}$.

Desde hace años, la doctrina viene criticando la exclusión de ciertas prestaciones de servicios profesionales del campo de aplicación del Derecho del Trabajo. El Derecho del Trabajo tiene vocación expansiva y, por ende, trata de convertirse en un Derecho de la actividad profesional que regule todas las prestaciones que por cuenta ajena, se lleven a cabo de forma dependiente o autónoma ${ }^{62}$. El contrato de ejecución de obra ofrece un buen ejemplo de cómo actualmente se están excluyendo del campo de aplicación de las normas laborales ciertas prestaciones de servicios llevadas a cabo de forma personal y por cuenta de otra persona, a cambio de una remuneración. Tal relación jurídica, a tenor de lo establecido en los artículos 1583 y siguientes del Código Civil, está -al igual que el arrendamiento de servicios- íntegramente modelada en la romana locatio conductio operis. Es sabido que en esta modalidad arrendaticia, la obligación contractual versa sobre la ejecución remunerada de "un trabajo"; por ejemplo, la construcción de una casa. El contrato de arrendamiento de obra se distingue del de servicios por razón del objeto que no es el trabajo en sí sino el producto del mismo, ya acabado. Debe alcanzarse el resultado apetecido. El que se compromete a poner el trabajo puede ejecutarlo como le plazca, sin someterse a las órdenes o instrucciones de la otra parte, puesto que sólo se obliga a poner a su disposición la obra terminada. El conductor operis, si busca el concurso de otras personas para realizar la obra, era responsable únicamente si hubiese hecho la sustitución desacertadamente, nombrando, por ejemplo, a persona no perita en el trabajo de que se tratara (Dig. 19,2,13,1). La teoría del Derecho común ha formado de éste y otros fragmentos el principio de la responsabilidad por la llamada culpa in eligendo. También era responsable por sus auxiliares

\footnotetext{
${ }^{60}$ Escudero Rodríguez, Los convenios colectivos y acuerdos de empresa, en VALDÉs (editor), La Reforma del Mercado Laboral (Valladolid, 1994), p. 41.

${ }^{61}$ Montoya Melgar, Derecho del Trabajo (18a edición, Madrid, 1996), p. 276.

${ }^{62}$ Sagardoy Bengoeche, Los trabajadores autónomos, cit. (n. 3), p. 29.
} 
como si la labor hubiera sido hecha por él mismo ${ }^{63}$. La nota común en los diversos casos de arrendamiento es su carácter remuneratorio, y es la naturaleza de la prestación lo que hace aparecer como especial cada tipo de contrato; pero para los romanos - para la doctrina civilista contemporánea- lo fundamental era la circunstancia de que en todos estos casos se alquilaba algo (locare), bien fuera una cosa o la ejecución de una obra o el trabajo de una persona ${ }^{64}$.

Lo mismo acaece en el contrato de ejecución de obra moderno, al que las empresas recurren cada vez en mayor medida en aras de soslayar una de las más severas y generalizadas recesiones de la historia. En el contrato de ejecución de obra, la causa es la misma que en el contrato de trabajo: la obtención de los frutos del trabajo humano. En aquella relación jurídica, el contratista se compromete a la consecución de un resultado para un tercero, mediante su trabajo libre y personal, y sin perseguir un lucro especial, sino simplemente una remuneración. Los elementos que en tal contrato resaltan de un modo especial son, por un lado, el resultado, y por otro, el hecho de conseguirlo fuera de la esfera del comitente, con autonomía. El contratista que trabaje personalmente mediante remuneración es un trabajador por cuenta ajena y, sin embargo, la jurisprudencia se ha mostrado renuente a aplicar las reglas laborales al contrato de ejecución de obra ${ }^{65}$. De gran importancia es la sentencia del Tribunal Supremo de 22 de febrero de 1954, que recoge con minuciosidad los rasgos distintivos de este contrato. En la locación de obra se retribuye el resultado; el riesgo corre a cargo del contratista; no se concierta salario, sino la retribución en que se calcula el coste de la obra; el contrato puede rescindirlo el dueño a su voluntad, con la oportuna indemnización (artículo 1594 CCEsp.), la dirección corresponde al contratista, sin más que sujetarse a las condiciones pactadas y, por eso, la realiza por su cuenta y riesgo, respondiendo del trabajo ejecutado por las personas que ocupe en la obra (artículo 1596 CCEsp.). Siguiendo un criterio constante el Tribunal Supremo concluye que el de ejecución de obra queda fuera del ámbito laboral. Lo mismo acaece con otros institutos jurídicos como el arrendamiento de servicios, mandato, comisión, etc.

${ }^{63}$ Daza-Rodríguez Ennes, Instituciones de Derecho Privado Romano (3a edición, Madrid, 2001), pp. 383-384.

${ }^{64}$ Ibíd., p. 383.

${ }^{65}$ Han estudiado exhaustivamente este contrato, García PiQueras, En las fronteras del derecho del Trabajo (Granada, 1999); y Martín VALVerde, Fronteras y zonas grises del Derecho del trabajo en la jurisprudencia actual (1980-2001), en Revista del Ministerio de Trabajo y Asuntos Sociales 38 (2002). 


\section{EPÍLOGO}

En las páginas que anteceden hemos tratado de dejar constancia de que las situaciones críticas son una constante en el proceso de evolución de las relaciones laborales, que han afectado al contrato de trabajo desde sus mismos orígenes. En todo caso se trata de un proceso condicionado por la tensión que sucesivamente ha ido enfrentando la autonomía del individuo con la heteronomía del Estado, o ésta con la autonomía colectiva ${ }^{66}$. Si en un principio fue necesaria la intervención legislativa para corregir la falacia del contrato libre, sólo la combinación equilibrada del intervencionismo estatal y de la actuación normativa de los grupos profesionales es la que históricamente ha propiciado la consolidación del Derecho del Trabajo como parcela del ordenamiento jurídico dotada de autonomía propia. Las nuevas circunstancias económicas y sociales derivadas de la globalización de los intercambios comerciales y del aumento imparable del desempleo están propiciando un proceso de signo inverso al hasta ahora recorrido; las exigencias de flexibilización apuntan a una diversificación de las relaciones laborales y a un intento de disolución del contrato de trabajo en esa relación de empleo de perfiles borrosos en la que se quieren encuadrar las diferentes formas de trabajo atípico o las derivadas de nuevas y complejas organizaciones productivas en las que, cada vez con mayor frecuencia, se produce el fenómeno de la externalización del trabajo y, consecuentemente, el intento de extraer a quienes lo prestan del campo del ordenamiento laboral para introducirlos en los dominios que regulan las prestaciones de servicios independientes, hasta el punto de que en la doctrina haya podido hablarse no sólo de parasubordinación ${ }^{67}$, sino incluso, de pseudocontratados de trabajo y pseudoempresarios ${ }^{68}$. Con todo, debemos convenir con Borrajo en que el Derecho laboral en general, y el español en concreto, aún está dominado por el modelo propio del trabajador industrial, urbano, estable en su relación de servicio, por lo que está anclado en principios típicos de 1931 a 1973; resulta así poco apto parar otorgar protección social eficaz a los trabajadores típicos de la sociedad postindustrial de los años actuales, en los que se quiere dar entrada a un proceso de movilidad permanente,

${ }^{66}$ Cfr., en general, SAgardoy, La libertad sindical y los espacios de la autonomía privada, en Documentación Laboral 24 (1998), pp. 9 ss.

${ }^{67}$ En la conocida expresión acuñada por la doctrina italiana. En la nuestra, véase al respecto: Ruiz Castillo, Delimitación subjetiva del Derecho del Trabajo. Un interrogante especifico: el trabajo parasubordinado, en Relaciones Labores. Revista Crítica de Teoría y Práctica 2 (1991), pp. 135 ss. y la bibliografía que cita.

${ }^{68}$ Gaudu, Du statut de l'emploi au statut de l'actif, en Droit Social 6 (1995), p. 537. 
valga la paradoja. La crisis del Derecho del Trabajo es, así, la crisis de una forma histórica del Derecho del Trabajo: la forma keynesiana posterior a la Gran Depresión de 1929.

En el último decenio, las ventajas y las consecuencias negativas de la globalización y la liberación del comercio han sido demostradas de muchas maneras. Las segundas han nutrido un temor cada vez más hondo a la inseguridad y la precariedad, que fomenta el proteccionismo y, por tanto, amenaza la economía mundial. Así las cosas, la aparición de las empresas multinacionales han generado la complejidad jurídica que supone regular sus actividades económicas transfronterizas, inclusive en el terreno de los derechos laborales. A mayor abundamiento, los Estados compiten entre ellos rebajando las normas laborales para facilitar el acceso al mercado y atraer inversiones a sus territorios y conseguir con ello una ventaja competitiva $^{69}$. Como las normas de la Organización Mundial de Comercio prohíben a los Estados miembros aumentar unilateralmente los aranceles aduaneros para proteger a los productores nacionales, los Estados pueden verse tentados a rebajar sus normas laborales ${ }^{70}$. En mi opinión también existe semejante competencia dentro de los Estados federales que, en España dado el peculiar sistema fiscal de algunas Comunidades Autónomas, genera notorios agravios comparativos. Estados y empresas deben basarse en el imperio de la ley si quieren evitar un sistema darwiniano en el que únicamente sobrevivan los más fuertes. Es, pues, de todo punto necesario que sedimente un amplio consenso en torno a la necesidad de fijar límites aceptables, para evitar retrocesos sociales en cadena, y de salvaguardar los derechos del trabajo fundamentales.

[Recibido el 13 de marzo y aceptado el 15 de abril de 2009].

\section{BIBLIOGRAFÍA}

Luján Alcaraz, La contratación privada de servicios y el contrato de trabajo (Madrid, 1994).

Albiol Montesinos y otros, La Reforma Laboral de 1997 (2a edición, Valencia, 1998).

Alemán-Castán, Del trabajo como hecho social al contrato de trabajo como realidad normativa: un apunte histórico-romanistico (Madrid, 1997).

Alonso Olea, Introducción al Derecho del Trabajo (Madrid, 1987).

${ }^{69}$ Kaufmann, Globalisation and Labour Rights. The Conflict betweeen Core Labour Rights and Internacional Economic Law (Oxford, 2007), passim.

${ }^{70}$ Véase, en este sentido: Cabeza Pereiro, El estatuto del trabajador autónomo español, en Revista Internacional del Trabajo 127 (2008), pp. 99 ss. 
Alonso Olea, Las raices del contrato de trabajo, en Anales de la Real Academia de Jurisprudencia y Legislación 21 (1989), pp. 339 ss.

Aristóteles, Politica.

Aristóteles, Rethorica.

BAYlos, Derecho del Trabajo modelo para armar (Madrid, 1991).

Bayón Chacón, La autonomía de la voluntad en el Derecho del Trabajo. Limitaciones a la libertad contractual en el Derecho histórico español (Madrid, 1955).

BERNARD, La rémuneration das profesions liberáles en Droit romain classique (París, 1936).

Blasco Pellicer, La individualización de las relaciones laborales (Madrid, 1995).

Borrajo, Introducción al Derecho del Trabajo (8a edición, Madrid, 1995).

Cabeza Pereiro, El estatuto del trabajador autónomo español, en Revista Internacional del Trabajo 127 (2008), pp. 99 ss.

Callejo De La Cuesta, Derecho Social (Madrid, 1935).

Casas BaAmonde, La individualización de las relaciones laborales, en Relaciones Laborales (1991).

Chacarategui, ¿Los encuestadores son trabajadores? (Madrid, 1996).

Cicerón, Ad Atticum.

Cicerón, De finibus.

Cicerón, De officiis.

Cícerón, De oratore.

D’Antona (editor), Politiche di flessibilitá e mutamenti del Diritto del Lavoro. Italia e Spagna (Napoli, 1990).

D'antona, La autonomía individual y las fuentes del Derecho del Trabajo, en Relaciones Labores. Revista Crítica de Teoría y Práctica 2 (1991).

Daza- Rodríguez Ennes, Instituciones de Derecho Privado Romano (3a edición, Madrid, 2001).

Daza-Rodríguez Ennes, Instituciones de Derecho Privado Romano (3a edición, Madrid, 2001).

De Aguinaga Tellería, Derecho del Trabajo (Madrid, 1952).

de Castro, Federico, Derecho Civil de España (Madrid, 1955).

De Robertis, Lavoro e lavoratori nel mondo romano (Bari, 1963).

Diéguez Cuervo, Derecho y trabajo (Madrid, 1963).

ERdmann, Frei Berufe und Arbeitsuerträge in Rom, en Zeitschrift der Savigny-Stiftung 79 (1948).

Escudero Rodríguez (editor), Reforma de la Legislación Laboral (Sevilla, 1997).

Escudero Rodríguez, Los convenios colectivos y acuerdos de empresa, en Valdés (editor), La Reforma del Mercado Laboral (Valladolid, 1994).

Escudero Rodríguez, Sobre la laboralidad de los mensajeros, en La Ley 4 (1996), pp. 795 ss.

Fhilippson; Das Sittlischöne bei Panaitos, en Philologus (1955).

Friedmann, Legal Theory (5a edición, Londres, 1967.

Fulbrook, Historia de Alemania (traducción española de B. G. Ríos, Cambridge, 1995).

Galiana Moreno, Crisis del contrato de trabajo, en Revista de derecho social 2 (1998).

GaLL, Bismarck: The White Revolutionary (Londres, 1986). 
Gallardo Moya, Viejo y nuevo trabajo a domicilio. De la máquina de hilar al ordenador (Madrid, 1998).

García Piqueras, En las fronteras del derecho del Trabajo (Granada, 1999).

Gaudu, Du statut de l'emploi au statut de l'actif, en Droit Social 6 (1995).

Gierke, Las raíces del contrato de trabajo (traducción española de. G. Barreiro, Madrid, 1982).

Giugni, Derecho del Trabajo. Voz para una enciclopedia, en Temas Laborales 13 (1987).

Gómez-Iglesias, La influencia del Derecho Romano en las modernas relaciones de trabajo (Madrid, 1995)

GonzÁlez Biedma Aspectos jurídico-laborales de las franquicias, en Revista Española de Derecho del Trabajo 97 (1999).

González Ortega, La presunción de existencia del contrato de trabajo, en Cuestiones actuales de Derecho del Trabajo (Madrid, 1990).

Guasp, Derecho (Madrid, 1971).

Hernainz Márquez, Tratado Elemental de Derecho del Trabajo (7a Edición, Madrid, 1955).

Kahn Freund, Legal Development. Labour Law, en Law and Opinion in England in the 20 Century (London, 1959) [= en Selected Writings (London, 1978)].

Kahn Freund, Trabajo y Derecho (traducción española de J. M. Galiana, Madrid, 1987).

Kaufmann, Globalisation and Labour Rights. The Conflict betweeen Core Labour Rights and Internacional Economic Law (Oxford, 2007).

Labowsky, Die Etik des Panaitos (Leipzig, 1933).

López Gandía, Contrato de trabajo y figuras afines (Valencia, 1999).

LöWENFELD, Inästabilität und Honorarung des artes liberales nach röm. Recht, en Festgabe Plank (Munich, 1887).

Luján AlCARAz, La contratación privada de servicios y el contrato de trabajo (Madrid, 1994).

Maluquer de Motes, La codificación civil en España, sintesis de un proceso, en Revista de Derecho Privado (1981), pp. 1083-1101.

Martín Granizo-González Rothvoss, Derecho Social (3a edición Madrid, 1935).

Martín Valverde, El discreto retorno al arrendamiento de servicios, en Homenaje al Prof. Alonso Olea (Madrid, 1990), pp. 125 ss.

Martín Valverde, Fronteras y zonas grises del Derecho del trabajo en la jurisprudencia actual (1980-2001), en Revista del Ministerio de Trabajo y Asuntos Sociales 38 (2002).

Martín Valverde, La formación del Derecho del Trabajo en España, en VV. AA. La legislación social en la Historia de España. De la revolución liberal a 1936 (Madrid, 1987), p. XI ss.

Montoya Melgar, "Presentación” a Sagardoy Bengoechea, Los trabajadores autónomos hacia un nuevo Derecho del Trabajo (Madrid, 2004).

Montoya Melgar, Derecho del Trabajo (18a edición, Madrid, 1996).

Montoya Melgar, Derecho del Trabajo (22a edición, Madrid, 2001).

Montoya Melgar, Derecho del Trabajo (28a edición, Madrid, 2007).

Montoya Melgar, Ideología y lenguaje en las leyes laborales de España: la crisis de 1917-1923 (Murcia, 1977). 
Montoya Melgar, Ideología y lenguaje en las leyes laborales de España: la dictadura de Primo de Rivera (Murcia, 1980).

Montoya Melgar, Ideología y lenguaje en las leyes laborales de la Segunda República (Murcia, 1983).

Montoya Melgar, Ideología y lenguaje en las primeras leyes laborales (Madrid, 1975).

OJedA, Autonomía colectiva y autonomía individual, en Relaciones Labores. Revista Crítica de Teoría y Práctica 2 (1991).

Ortiz Lallana, La transformación del Derecho del Trabajo ante los nuevos retos sociales (Lección inaugural del curso académico 1999-2000, Universidad de La Rioja, 1999).

Paladini, Cicerone, en Revista Ciceroniana 1 (1959).

Palomeque, Derecho del Trabajo e ideología (3a edición, Madrid, 1987).+

Palomeque-Cabero, Todo sobre las primeras normas de Reforma del Mercado de Trabajo (Barcelona, 1994)]

Planitz, Principios de Derecho Privado Germánico (traducción española de Melón Infante, Barcelona, 1957).

RADBRUCH, Einfürung in die Rechtwissenschaft (Leipzig, 1925).

Renner, The Institutions of Private Law and their Social Functions (Londres, 1949).

Rodríguez Ennes, Aproximación a la Historia Jurídica de Galicia (Santiago de Compostela, 1999).

Rodríguez Ennes, Influencia del Proyecto de 1851 en los códigos Iberoamericanos, en Actas del II Congreso Internacionaly VIberoamericano de Derecho Romano (Madrid, 2001), pp. 257 ss.

Rodríguez EnNes, La crisis de la autonomía de la voluntad y la aparición del moderno contrato de trabajo, en A autonomía da vontade e as condiçôes Gerais do contrato, de Roma ao direito actual. Anais do V Congreso Internacional y VIII Iberoamericano de Derecho Romano (Fortaleza, Ceará, Brasil, 2002), pp. 629 ss.

Rodríguez Ennes, La recepción del Derecho Romano en Inglaterra, en Actas del I Congreso Iberoamericano de Derecho Romano (Granada, 1997), pp. 203 ss.

Rodríguez EnNes, La remuneración de la oratoria forense: del rechazo inicial a su aceptación social y normativa, en Studi in memoria di Giambattista Impallomeni (Milano, 1999), p. 348 ss.

Rodríguez EnNes, Reflexiones en torno al origen de los honorarios de los "advocati", en SDHI. 60-61 (1994-1995): Studi Romanistichi in memoria di Gabbio Lombardi, pp. 361 ss.

Rodríguez-Piñero Royo y Calvo Gallego, Las relaciones laborales en los medios de comunicación, en CRUZ VILlalón (editor), Trabajo subordinado y trabajo autónomo en la delimitación de las fronteras del Derecho del Trabajo. Estudios en homenaje al profesor José Cabrera Bazán (Madrid, 1999).

Rodríguez-Piñero, Diritto del lavoro e mercato, en Lavoro e Diritto 1 (1995).

Rodríguez-Piñero, La huida del Derecho del Trabajo, en Relaciones Labores. Revista Crítica de Teoría y Práctica 1 (1992).

Rodríguez-Piñero, La voluntad de las partes en la calificación del contrato de trabajo, en Relaciones Labores. Revista Critica de Teoría y Práctica 2 (1996).

Rodríguez-Piñero, La voluntad de las partes en la calificación del contrato de trabajo, en Relaciones Labores. Revista Crítica de Teoría y Práctica 18 (1996).

Rojo Torrecilla (editor) Las Reformas Laborales de 1994 y 1997 (Madrid, 1998). 